\title{
Research on Ecological Environment Stress Effect of the Urbanization Process in Xianning, Hubei Province, China
}

\author{
Tian Lixue \\ School of Geography Sciences, South China Normal University, Guangzhou, China
}

Email address:

li-xue.tian@m.scnu.edu.cn

To cite this article:

Tian Lixue. Research on Ecological Environment Stress Effect of the Urbanization Process in Xianning, Hubei Province, China. International Journal of Environmental Monitoring and Analysis. Vol. 3, No. 5, 2015, pp. 357-363. doi: 10.11648/j.ijema.20150305.28

\begin{abstract}
With the rapid development of urban economy and the rapid increase of city population, the ecological environment stress effect of the urbanization process is increasingly prominent. The article is based on 2007-2012 statistical yearbook of Xianning City, Hubei Province, China, and two subsystems of urbanization development and ecological environment are estabilished respectively. The principal components analysis (PAC) is taken to determine the comprehensive level of both systems, and to determine the relative changes during these years by comparing the comprehensive level of them. Regression analysis method is used to calculate the related indices between urbanization rate and ecological environment, such as discharge amount of sewage, production of solid wasted and amount of exhaust emission, and to explore the urbanization concrete stress effect on the ecological environment, namely the concrete stress effect of urbanization development on the water environment, soil environment and atmospheric environment. Results show that there is linear correlation between urbanization rate and ecological environment. The increase of urbanization rate brings seriously negative impact on ecological environment. And based on this, the article makes some scientific suggestions for the coordinate development between urbanization process and ecological environment.
\end{abstract}

Keywords: Xianning City, Urbanization, Ecological Environment, Stress Effect

\section{中国湖北省咸宁市城市化进程对生态环境的胁迫效应研究}

\section{田丽雪}

地理科学学院, 华南师范大学, 广州, 中国

\section{邮箱}

li-xue.tian@m.scnu.edu.cn

摘要：随着城市经济的高速发展和城市人口的急剧增加, 城市化对生态环境产生的胁迫作用日益突出。本文以中国湖 北省咸宁市 (以下简称咸宁市) 2007-2012年统计年鉴数据为基础, 分别建立城市化与生态环境的两个子系统, 运用主 成分分析法确定两大子系统的综合发展水平，把两者进行对比分析，确定两者在这几年期间的相对变化情况；利用回 归分析方法进一步定量分析咸宁市城市化率与咸宁市废水排放量、固体废物产生量、废气排放量指标之间的关系，来 探讨咸宁市城市化进程对生态环境的具体胁迫效应，即城市化发展对水环境、土壤环境和大气环境的具体胁迫效应。 结果表明, 城市化率与生态环境之间存在着线性相关关系, 随着咸宁市城市化率的提高, 生态环境受到严重的负面影 响。并在此基础上提出咸宁市城市化进程与生态环境协调发展的科学建议。

关键词: 咸宁市, 城市化, 生态环境, 胁迫效应 


\section{1. 引言}

城市化又称城镇化, 是当今世界最重要的社会经济现 象之一。城市的发展是该区域自然、政治、经济等因素综 合作用的结果, 其中生态环境更是城市化进程中一个重要 的因素。随着城市经济的高速发展和城市人口的急剧增加, 城市化对生态环境产生的胁迫作用日益突出, 几乎全世界 的每一个城市都存在不同程度的水资源短缺和生态恶化 问题，日益成为令人关注的焦点。生态环境与城市发展之 间有着密切的关系, 城市化通过城市居民的行为改变着生 态环境: 城市化通过人口增加、经济发展、能源消耗和交 通扩张对生态环境产生威胁, 这种驱动下原生态环境迅速 向次生态环境转变, 其结果往往是生态质量下降。探讨城 市化发展对生态环境胁迫影响, 分析城市化进程中生态环 境变化规律, 对中国城市化的发展、生态资源持续利用以 及生态环境保护都具有重要意义。目前, 咸宁市正处在经 济发展的加速阶段, 研究此区域生态环境对城市化发展的 响应以及治理对策有着十分重要的现实意义。

\section{2. 研究进展}

\section{1. 国际研究回顾}

随着城市经济的高速发展和城市人口的急剧增加, 城 市发展对周围地区的生态环境造成的污染和破坏越来越 严重, 城市化进程中对生态环境产生的胁迫作用也逐渐引 起了国际学者的高度关注。主要表现有两个方面: 一是非 常重视城市经济发展及空间扩张所带来的水资源紧张、环 境污染、生态破坏等问题, 以及脆弱的生态环境对城市化 的约束和限制作用, 如: Salman认为快速的城市化和工业 化导致印度干旱地区出现了严重的生态退化现象 [1]; 如 Pouraghniaei认为城市化改变了生态环境状况, 如污染和 生态危机, 使人们开始思考更深层次的发展 [2]; 二是涌 现了一系列研究城市发展及城市化与生态环境关系的理 论, 如环境库兹涅茨曲线假说 (EKC) [3]、关键性自然资产 理论 (CNC) [4]、生态经济学理论 (EE) [5]、生态城市理论 (EC) $[6]$ 等。

\section{2. 中国研究回顾}

随着人类日新月异的发展城市化已成为时代进步的 标志, 但是城市化发展过程中必须遵守自然规律、社会规 律统筹兼顾, 使生态环境和人类家居和谐相容。研究城市 化和生态环境是一个重要的课题, 对于城市化进程与生态 环境之间关系的研究, 从中国研究看来, 主要有三个方向。 一是对城市化与城市生态环境关系的研究, 例如耦合关系、 和谐度或者对比关系的研究, 例如罗会永从城市化对生态 环境的胁迫效应和城市化对生态环境的约束效应两方面 进行扩展分析 [7]; 如安瓦尔 - 买买提明等基于模糊数学 对新疆南疆地区的城市化与生态环境和谐度分析 [8]; 如 陈健等利用熵权的层次分析法和模糊数学理论方法, 建立 城市化与生态环境和谐度评价体系模型 [9]; 如刘少博等
基于气候方面的资料分析了长沙市城市化和生态环境之 间的和谐关系 [10]; 如丁婷红运用模糊隶属度函数进行量 化, 对新疆南部城市的城市化与生态环境对比研究 [11]; 如王静等根据协同论的思想构建协调发展模型进而评价 城市化与生态环境发展的协调状况 [12]。

二是突出水资源匮乏与短缺在城市城市化进程中的 约束作用, 例如冯兰刚等认为在城市化进程中必须把生态 建设, 特别是水生态建设作为 “可持续发展” 的重点, 坚 持 “人水相亲、自然和谐” 的水生态安全理念 [13]; 如乔 标等对干旱地区城市化与生态环境交互胁迫过程研究在 理论、观点、方法与实践等方面取得的最新进展进行了系 统的总结 $[14]$ 。

三是对城市化过程中关于生态环境发展的一些理论 研究或者应用, 例如白艳莹从土地利用和景观格局、资源 环境、生态足迹占用的变化三个方面评价分析了城市化过 程引发的各种生态环境效应 [15]; 如邹仁爱等将生态学的 胁迫概念引入到城市的可持续发展领域中, 并为解决城市 可持续发展提供了一条行之有效的发展模式 [16]; 如郭娅 琦指出城市化受到生态环境不同程度的制约, 研究了城市 化影响生态环境的具体过程 [17]; 如周玄德等运用GM (1:1) 模型对吐鲁番市城市化与生态环境的综合指数进行预测, 探讨城市化与生态环境的动态发展状况 [18]; 如路春燕等 是基于 $\mathrm{BP}$ 神经网络来对延安市进行城市化发展生态环境 压力响应研究 [19]; 如李云等通过研究中国城市化发展面 临的资源环境形势和生态环境形势, 提出资源生态环境约 束下我们城市化路径选择 [20]。

\section{3. 总结}

从研究进展来看, 中国对此问题的研究成果显著, 并 与区域的可持续发展相衔接, 但仍存在二方面问题: 其一 是城市化进程与生态环境关系研究大多数研究仍停留在 定性描述阶段, 定量研究较少; 其二是目前有关城市化对 生态环境的影响分析大多集中于大城市, 对中小城市尤其 是中西部地区的小城市的研究很少。

\section{3. 研究区域概况}

\section{1. 咸宁市概况}

咸宁市位于湖北省东南部，长江中游南岸，湘鄂赣三 省交界处, 是南下北上的主要通道, 有 “湖北南大门”之 称, 是武汉城市群的核心城市之一。地理位置跨东经 $113^{\circ} 33^{\prime}-114^{\circ} 58^{\prime}$, 北纬 $29^{\circ} 01^{\prime}-30^{\circ} 17^{\prime}$, 全市现辖 4 县 1 市 1 区, 共 12 个乡、 51 个建制镇、 6 个办事处。地势南 高北低, 地貌复杂多样, 山、丘、岗、平兼而有之。截至 2011年底, 全市国土面积9861平方公里。咸宁市属亚热带 大陆性季风气候, 气候温和, 降水充沛, 日照充足, 四季 分明, 无霜期长。冬季盛行偏北风, 偏冷干燥; 夏季盛行 偏南风, 高温多雨。年平均气温 $16.8^{\circ} \mathrm{C}$, 极端最高气温 $41.4^{\circ} \mathrm{C}$, 极端最低气温为零下 $15.4^{\circ} \mathrm{C}$ 。年平均降水量 1577. 4 毫米, 年平均日照时间为 1754.5 小时, 年平均无霜 
期为245-258天。主要灾害性天气有倒春寒、大暴雨、水 灾、洪涝及夏旱、伏旱。

经济总量跨越新台阶。经初步核算, 全年全市完成地 区生产总值760.99亿元, 比上年增加108.98亿元, 实现了 连续三年突破 100 亿元的发展, 按可比价计算比上年增长 $12.2 \%$ 。其中, 第一产业完成 145.30 亿元, 增长 $4.7 \%$; 第 二产业完成359.73亿元, 增长 $16.3 \%$; 第三产业完成 255.96 亿元, 增长 $10.2 \%$ 。三次产业结构由去年的 18.2: 47.4: 34. 4 调整为 $19.1: 47.3: 33.6$ 。

\section{2. 数据来源与处理}

本文采用湖北省统计年鉴（2007-2012）、中国城市 统计年鉴 (2007-2012)、中国环境统计年鉴 (2007-2012) 等统计数据, 建立城市化与生态环境系统评价指标体系, 借助主成分分析方法, 对咸宁市城市化、生态环境分别测 算综合水平指数, 然后在进行细部定量分析, 借助回归分 析, 将咸宁市城市化率分别与生态环境中的废气排放量、 固体废物产生量、废气排放量之间进行计算分析, 来探讨 咸宁市城市化进程对生态环境的具体的胁迫效应。

本文研究所用数据主要来源是湖北省统计年鉴 （2007-2012），结合本市具体情况，从人口城市化、经 济城市化、空间城市化和社会生活城市化四个层面出发, 共选取了反映城市化水平的 13 项指标对咸宁市城市化综 合水平进行综合测度, 以及从生态环境状态、生态环境压 力和生态环境响应的 11 项指标对咸宁市的生态环境综合 水平进行评价。

\section{4. 研究方法}

\section{1. 城市化与生态环境胁迫效应研究指标体系的建立}

\subsection{1. 城市化指标体系的建立}

城市化是指人口向城市地区集中和农村地区转变为 城市地区的过程, 它包括人口增长、经济发展、空间扩展 和生活提高等方面和其间的相互作用, 其中经济发展是基 础, 人口增长和地域扩张是表现, 生活水平的提高是最终 结果。因此, 综合相关文献与研究目标 [21], 本文从人口 城市化、经济城市化、空间城市化、社会生活城市化四个 方面选取了13个指标（见表1）。

人口城市化包括总人口、人口密度、城镇人口比重和 第三产业从业人口比重这4项指标; 经济城市化包括工业 生产总值、人均生产总值和第三产业比重这 3 项指标; 空 间城市化包括人均建成区面积和人均道路面积这 2 项指标; 社会生活城市化包括社会消费品零售总额、城镇居民可支 配收入、医疗床位数和每万人约有公共交通车辆这 4 项指 标。

\section{1.2. 生态环境评价因子的建立}

生态环境不仅包括人类与生物赖以生活和生存的自 然环境要素, 还包括影响人类和生物有利与不利的生态因 子。本文参考经济合作和开发组织与联合国环境规划署共 同提出的生态环境指标PSR概念模型, 即压力---状态---
相应模型, 从生态环境状态、生态环境压力、生态环境响 应三方面选取了11个指标（见表1）[22]。

生态环境状态包括园林绿地面积、建成区园林覆盖面 积、造林面积、耕地面积和人均公园绿地面积这5项指标; 生态环境压力包括废水排放量、固体废弃物排放量和废气 排放量这3项指标; 生态环境响应包括城市人均日生活用 水量、工业废水排放达标率和工业固体废物综合利用率这 3项指标。

表1 城市化与生态环境系统评价指标体系。

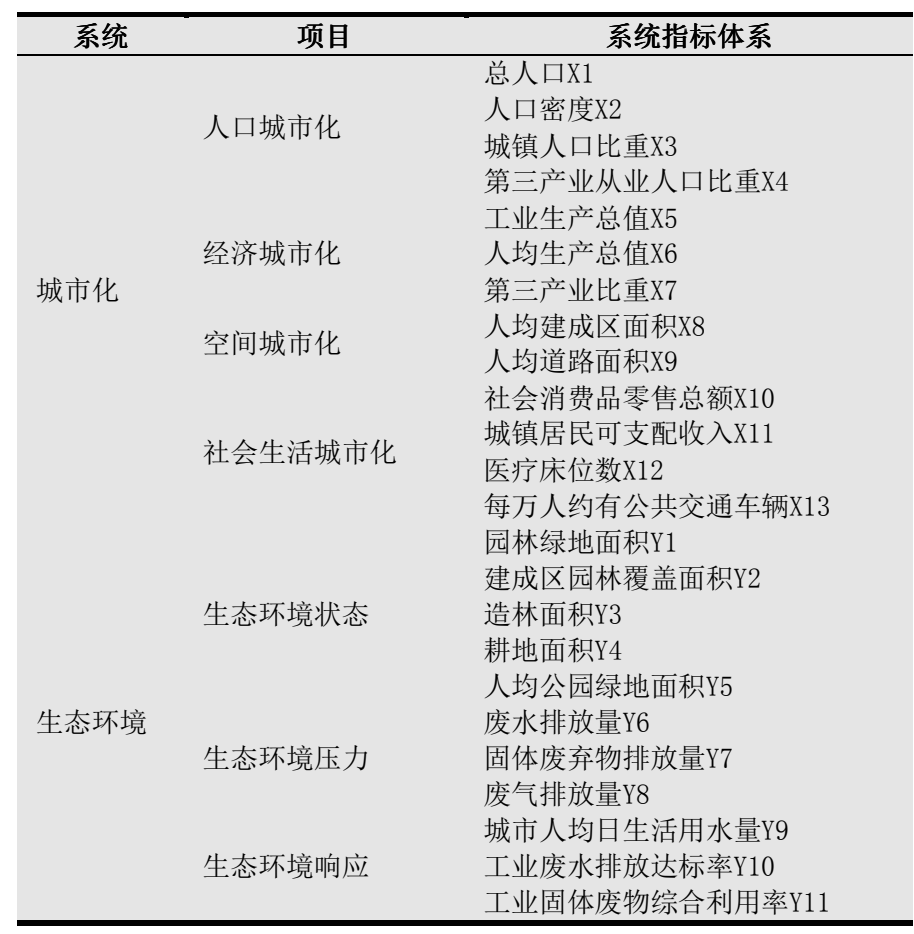

资料来源：湖北省统计年鉴（2007-2012）; 中国城市统计年鉴 （2007-2012）；中国环境统计年鉴（2007-2012）

\section{2. 计算方法}

\subsection{1. 城市化与生态环境综合发展水平的评价一主成分 分析}

为克服多指标变量间信息重叠及人为确定指标权重 的主观性, 文章运用主成分分析方法分别测算咸宁市城市 化和生态环境的综合发展水平。主成分分析方法就是考虑 各指标之间的相互关系, 利用降维的方法将多个指标转换 为少数几个互不相关的指标, 从而使进一步研究变得简单 的一种统计方法。利用统计分析软件SPSS19. 0对标准化 后的城市化水平指标进行主成分分析, 用主成分法提取公 因子, 按特征值大于 1 的原则, 提取主因子, 起到了降维 的作用。具体方法是:

首先, 采用标准差标准化方法对原始数据进行标准化 计算。按Xi $\mathrm{j}=(X i j-X j) / \operatorname{Sqrt}(\operatorname{Var}(X j))$ 进行标准化处理, 使每个属性均值为 0 , 方差为 1 ;

然后, 对原始变量进行相关分析, 计算原始变量之间 的相关系数矩阵, 确定待分析的原有若干变量能够进行主 成分分析; 
其次，用主成分模型的主成分分析提取公因子，对初 始因子载荷矩阵进行方差最大法正交旋转后, 得到主因子 旋转载荷矩阵，使主成分具有更明显的解释意义;

再次, 计算因子变量得分, 将成份得分系数矩阵A作 为主因子的系数, 然后计算出城市化水平综合得分和生态 环境水平综合得分, 从而达到对城市化以及生态环境综合 测度的目的。

定义城市化发展评价函数为 $\mathrm{F}(\mathrm{x})$, 生态环境状况评价 函数为 $\mathrm{G}(\mathrm{y})$ ，利用主成分得分构建函数 [23-24]:

$$
\mathrm{F}(\mathrm{x})=\sum_{i=1}^{n} W_{i} F_{i}(i=1,2,3, \ldots)
$$

式中: $F(x)$ 是城市化发展评价函数; $F i$ 为对城市化指 标进行因子分析所选取的第 $i$ 个主成分得分; Wi 为利用主 成分分析所得的第 $\mathrm{i}$ 个主成分的权重, 以每个主成分所对 应的特征值占所提取主成分总的特征值之和的比例作为 权重。即： $W_{i}=a i /\left(a_{1}+a_{2}+a_{3}+\cdots+a_{n}\right)\left(a_{1}, a_{2}, \cdots, a_{n}\right.$ 为对应的 各个主成分特征值)。生态环境状况评价函数 $\mathrm{G}(\mathrm{y})$ 的构成 形式与 $\mathrm{F}(\mathrm{x})$ 相同。

\subsection{2. 城市化进程对生态环境的胁迫效应评价方法一回 归分析}

回归分析是指通过提供变量之间的数学表达式来定 量描述变量间相关关系的数学过程。线性回归假设因变量 与自变量之间为线性关系, 用一定的线性回归模型来拟合 因变量和自变量的数据, 并通过确定模型参数来得到回归 方程。本文用到的是一元线性回归, 数学模型为: $\mathrm{E}(\mathrm{y})=\beta_{0}+\beta_{1 \mathrm{x}}$

本文利用回归分析法研究咸宁市城市化进程对生态 环境的胁迫效应, 选取上述生态环境指标中的废水排放量、 固体废弃物排放量和废气排放量这3项指标，与近几年的 城市化率进行回归分析, 得出相关系数和回归方程。

相关系数: $\quad \mathrm{r}=\frac{n \sum x y-\sum x * \sum y}{\sqrt{n \sum x^{2}-\left(\sum x\right)^{2}} * \sqrt{n \sum y^{2}-\left(\sum y\right)^{2}}}$

回归方程: $y=a+b x$

式中: $\mathrm{b}=\frac{n \sum x y-\sum x * \sum y}{n \sum x^{2}-\left(\sum x\right)^{2}}, \mathrm{a}=\sum \frac{y}{n}-b * \sum \frac{x}{n}$

\section{5. 城市化与生态环境效应分析}

\section{1. 城市化与生态环境综合发展水平}

按照上述城市化与生态环境综合发展评价方法, 利用 SPSS软件对原始数据进行标准化处理和主成分分析。主成 分个数提取的原则是主成分对应的特征值 $\geqslant 1$ 的前 $\mathrm{N}$ 个主 成分, 选取特征值大于 1 的主成分和相应的该线路和累计 贡献率。（见表2, 表3）

表2 城市化主成分特征值及主成分贡献率。

\begin{tabular}{llll}
\hline 主成分F & 特征值 & 贡献率/\% & 累积贡献率/\% \\
\hline 1 & 7.877 & 60.595 & 60.595 \\
2 & 2.928 & 22.522 & 83.117 \\
3 & 1.108 & 8.524 & 91.642 \\
\hline
\end{tabular}

表3 生态环境主成分特征值及主成分贡献率。

\begin{tabular}{llll}
\hline 主成分 $\mathrm{F}$ & 特征值 & 贡献率/\% & 累积贡献率/\% \\
\hline 1 & 5.847 & 53.158 & 53.158 \\
2 & 2.891 & 26.278 & 79.436 \\
3 & 1.279 & 11.628 & 91.064 \\
\hline
\end{tabular}

利用公式 (1) 构建城市化与生态环境综合发展水平 的评价函数 $\mathrm{F}(\mathrm{x})$ 和 $\mathrm{G}(\mathrm{y})$, 表达式如下

$$
\begin{aligned}
& F(x)=0.606 * F 1+0.225 * F 2+0.085 * F 3 \\
& G(y)=0.532 * F 1+0.263 * F 2+0.116 * F 3
\end{aligned}
$$

将所得到的主成分得分带入式 (4) 、式 (5)，可以 得到2006-2011年每年咸宁市城市化与生态环境的综合发 展水平指数, 再将所得的指数用SPSS软件进行制图处理 （见图1）。

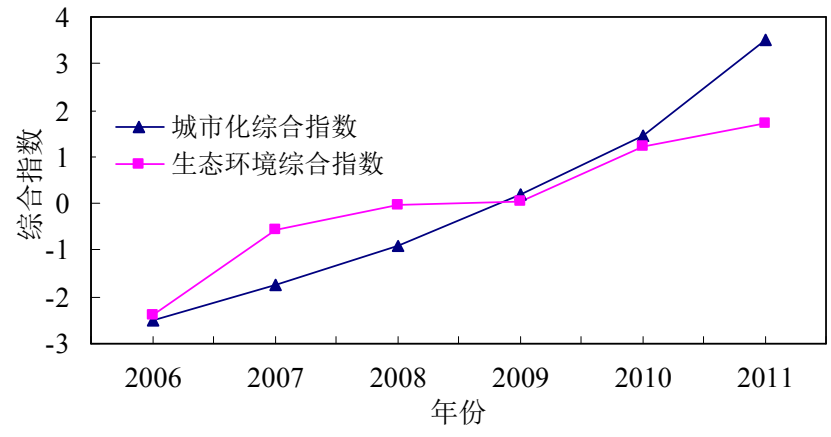

图1 咸宁市城市化与生态环境综合发展水平。

从图1可以看出, 咸宁市2006-2011年期间城市化与生 态环境综合发展水平整体呈上升趋势, 城市化发展指数每 年平均上升 1.02 个点, 生态环境指数每年平均上升 0.8 个 点, 可见城市化发展速度快于生态环境发展速度。根据城 市化与生态环境交互作用机理可将其发展过程大致分为 两个阶段: 2006年-2009年期间两者的综合指数都比较低, 城市化综合发展指数稳定增长, 而生态环境综合发展指数 增长幅度略大于城市化综合发展指数; 2009年以后生态环 境综合发展指数增长缓慢趋于平缓, 城市化综合发展指数 有明显的增幅, 呈现出显著快速发展的态势。

\section{2. 咸宁市城市化进程对生态环境的胁迫效应}

随着城市的高速发展, 城市人口也相应的急剧增加 （表4）, 人口的增加和人口的密集对生态环境的胁迫作 用日益突出, 人类的生产生活需要耗费大量的资源和能源, 对有限的水资源、土地资源等造成了很多的压力, 湖北省 咸宁市的城市化进程亦是如此。比如说人类的生产生活会 产生许多的废气、废物和废气, 这些废弃物排放到环境中 对生态环境必然会造成破坏。当其总量超过自然环境的承 载能力时, 就会导致生态环境的污染, 甚至是生态环境的 退化, 后果不堪设想, 最终也会阻碍城市的进一步发展, 对现在高速发展的城市化进程进行限制, 进而威胁人类的 生产。城市化进程对生态环境造成了极大的胁迫效应, 值 得我们注意。 
本文以咸宁市2006-2011年的数据，进一步定量分析 咸宁市城市化率与咸宁市废水排放量、固体废物产生量、 废气排放量之间的关系, 来探讨咸宁市城市化进程对生态 环境的具体的胁迫效应。

表4 咸宁市城镇人口年度变化。

\begin{tabular}{llll}
\hline 年份 & 总人口/万人 & 城镇人口/万人 & 城市化率/\% \\
\hline 2006 & 281.76 & 71.55 & 25.39 \\
2007 & 286.08 & 80.23 & 28.04 \\
2008 & 288.21 & 81.04 & 28.12 \\
2009 & 290.62 & 79.22 & 27.26 \\
2010 & 290.96 & 105.14 & 36.14 \\
2011 & 295.25 & 110.49 & 37.42 \\
\hline
\end{tabular}

注: 数据来源于湖北省统计年鉴

\subsection{1. 城市化进程对水环境的胁迫效应}

水资源是人类生存必备的物质条件，人类的生产、 生活都离不开水资源, 水资源可分为地表水和地下水两 部分。咸宁市水资源比较丰富, 全市水资源总量 135.2 亿 $\mathrm{m}^{3}$ ，其中地表水资源量 133.3 亿 $\mathrm{m}^{3}$ ，地下水资源21.96 亿 $\mathrm{m}^{3}$, 全市人均占有水资源总量 $4646 \mathrm{~m}^{3}$ 。但是, 人类在使
用水资源的同时也向水体排放大量的污染物，对水环境 造成很大的污染。从表 5 可以看出, 废水排放量从 2006 年的 2683 万吨递增到2011年的2957万吨。将咸宁市各年 度的城市化率与废水排放量进行回归分析, 依据相关系 数计算公式, 由 $r$ 的值来确定两者之间的相关分析。经计 算得出废水排放量与城市化率的相关系数 $r=0.892$, 表明 两者呈线性显著正相关关系, 回归方程为 $\mathrm{y}=2195.197+2131.393 \mathrm{x}$ 。由图2可以看出, 城市化进程对 城市水环境造成了很大的胁迫效应。

表5 咸宁市废水排放量年度变化。

\begin{tabular}{ll}
\hline 年份 & 废水排放量/万t \\
\hline 2006 & 2683 \\
2007 & 2763 \\
2008 & 2856 \\
2009 & 2949 \\
2010 & 2954 \\
2011 & 2957 \\
\hline
\end{tabular}

注：数据来源于湖北省统计年鉴、咸宁统计年鉴。下同。

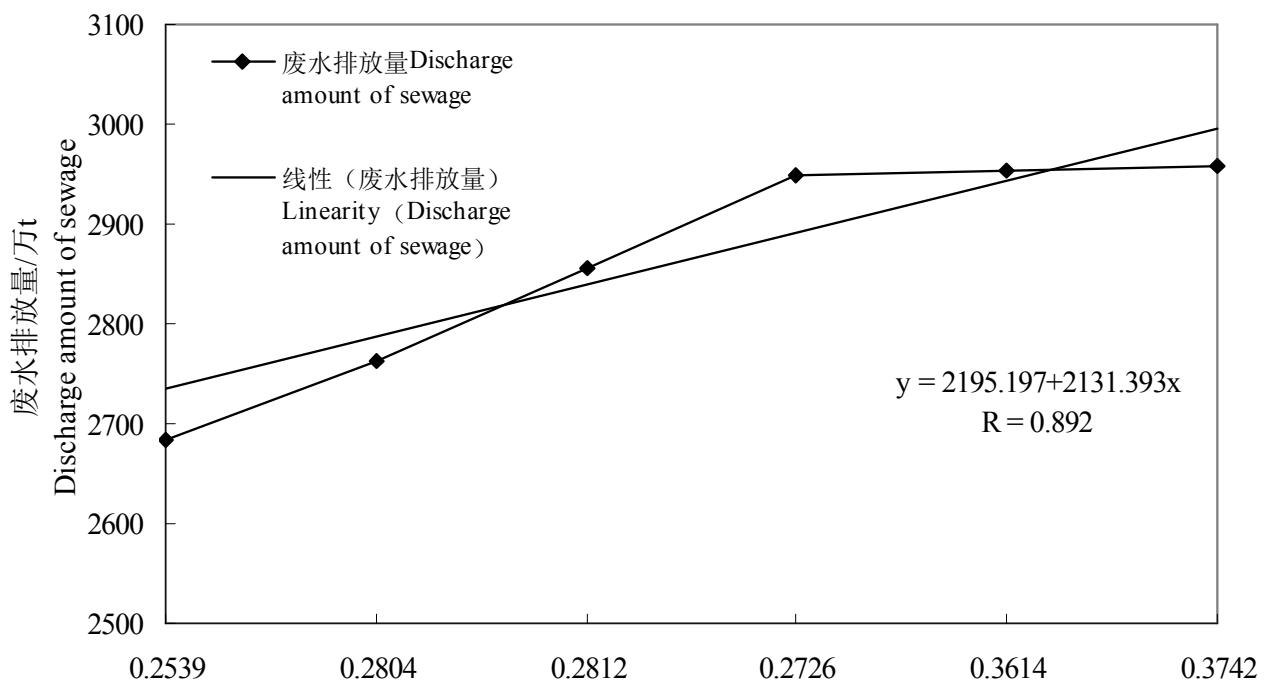

城市化率 Urbanization rate/\%

图2 咸宁市城市化率与废水排放量关系。

\subsection{2. 城市化进程对土壤环境的胁迫效应}

土壤资源是人类农业生产的基础条件，同时也是植物 赖以生存的必要物质保障。城市化进程对土壤同样也会造 成影响。城市的发展需要占用更多的土地面积作为建设用 地，使土地的供需矛盾日益严重。而且工业的发展会产生 大量的废弃物、污染物, 如果处理不当, 直接投放到土壤 之中, 也会污染土壤环境。本文采用固体废物产生量这个 指标来定量分析城市化与土壤环境之间的关系。

从表 6 可以看出, 固体废物产生量从 2006 年的 68 万吨 递增到2011年的134. 21万吨。将咸宁市各年度的城市化率 与固体废物产生量进行回归分析, 经计算得出固体废物产 生量与城市化率的相关系数 $r=0.945$, 表明两者呈线性显
著正相关关系, 回归方程为 $y=-75.606+564.594 x$ 。由图3 可以看出, 城市化进程对城市土壤环境造成了一定的胁迫 效应, 应该引起人们的高度重视。

表6 咸宁市固体废物产生量年度变化。

\begin{tabular}{ll}
\hline 年份 & 固体废物产生量/万t \\
\hline 2006 & 68 \\
2007 & 70 \\
2008 & 98.25 \\
2009 & 100.13 \\
2010 & 132.92 \\
2011 & 134.21 \\
\hline
\end{tabular}




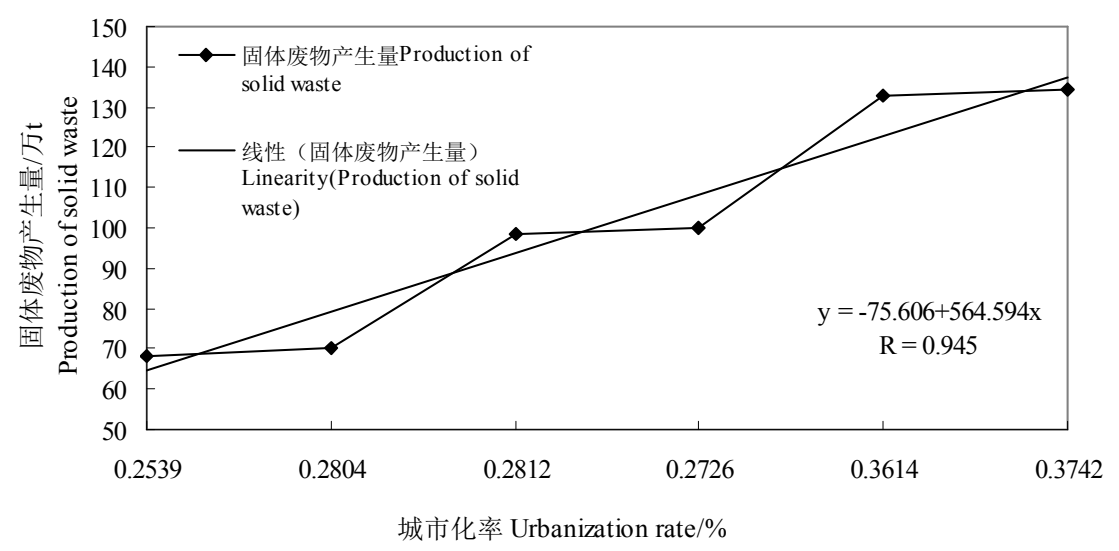

图3 咸宁市城市化率与固体废物产生量关系。

\subsection{3. 城市化进程对大气环境的胁迫效应}

城市化进程带动了经济的发展, 工业也随之快速发展 起来，工业规模的扩大也导致污染物排放量的增加，城市 化率的提升必然带来人口聚集，资源消耗量大，污染物的 排放量也越来越大，比如大气污染物的排放。本文采用废 气排放量这个指标来定量分析城市化与大气环境之间的 关系。

表7 咸宁市废气排放量年度变化。

\begin{tabular}{ll}
\hline 年份 & 废气排放量/亿立方米 \\
\hline 2006 & 265.65 \\
2007 & 292.31 \\
2008 & 295.37 \\
2009 & 359.12 \\
2010 & 404.40 \\
2011 & 490.25 \\
\hline
\end{tabular}

从表 7 可以看出, 废气排放量从 2006 年的 265.65 亿立 方米递增到2011年的490.25亿立方米。将咸宁市各年度的 城市化率与废气排放量进行回归分析, 经计算得出废气排 放量与城市化率的相关系数 $r=0.967$, 表明两者呈线性显 著正相关关系, 回归方程为 $y=-178.802+1698.310 x$ 。由图 4 可以看出, 城市化进程对城市大气环境也造成了一定的 胁迫效应, 应该引起人们的足够重视。

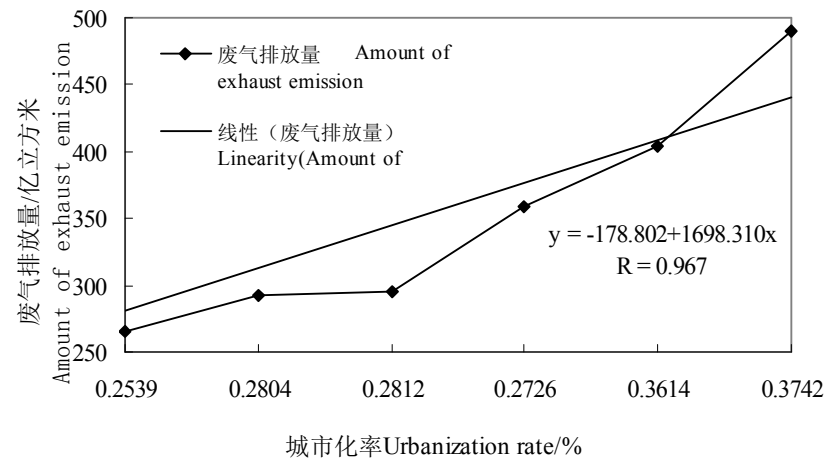

图4 咸宁市城市化率与废气产生量关系。

\section{6. 总结及建议}

\section{1. 总结}

从以上的咸宁城市化进程对水环境、土壤环境和大气 环境的胁迫效应的具体分析可以看出, 咸宁市的城市化发 展对生态环境已经造成了一定的胁迫效应, 我们应当重视 起来, 其影响与后果不容忽视。并且通过可以比较看出, 城市化率与大气环境指标之间的相关系数最高, 说明城市 化发展生态环境中的大气环境造成的负面压力最大, 最应 该引起我们的高度重视; 其次城市化进程对生态环境造成 较大影响的是土壤环境; 再次是生态环境中的水环境, 咸 宁市是水资源较为丰富, 因此对城市化发展所产生的水环 境破坏和污染的净化以及调节能力比较强, 没有像城市化 发展造成的大气环境和土壤环境影响那么剧烈, 但是水资 源也是我们生产生活的重要资源, 我们也必须引起极大的 重视。

\section{2. 建议}

\subsection{1. 提供大气环境污染治理工作力度}

大气环境的状态之间会对人类的身体健康造成危害, 因此大气环境污染治理工作很重要。治理大气污染, 首先 应调整能源结构, 建议使用清洁能源, 减少二氧化硫和烟 尘的排放量; 其次是政府相关部门应出台有利政策, 控制 车辆尾气排放, 从而缓解大气污染。

\subsection{2. 加强固体废弃物的治理工作}

一方面, 提高资源能源的利用率, 同时注重科学技术 研究, 将废弃物资源化, 并且相应减少污染物的排放, 提 倡可持续发展; 另一方面, 提高废弃物的无害化处理方法 和技术, 使废弃物对土壤环境等造成的危害程度减到最小。

\section{2.3. 提高水资源保护}

首先, 要保护好水源头, 不受污染, 环保部门要对工 厂排废水情况等做最严格的规定, ; 其次, 要提高水资源 的利用率, 主要采取多循环利用, 废水加工处理再利用等 方法, 既节约用水, 也减少了水资源的污染。 


\section{2. 4. 提高公民生态环境保护意识}

要加强宣传教育, 提高人们对生态环境的保护意识, 增强人们节约、合理利用资源的理念，营造公民之间互相 监督的意识, 从而实现城市健康可持续发展。

\section{致谢}

基金项目：国家自然科学基金（41571187）资助。

\section{参考文献}

[1] Salman M A Salman, Inter-states water disputes in India: an analysis of the settlement process, Water Policy, 2002, 4(3): 223 237.

[2] MJ Pouraghniaei. Effects of Urbanization on Quality and Quantity of Water in the Watershed [M/OL]. Availablefrom: www. enpe. $\mathrm{fr} /$ cereve/HomePages/theveno t/www-jes-2002/Pouraghniaei-Paper-2002. Dec.

[3] Soumyananda Dinda. Environmental Kuznets Curve Hypothesis: A Survey. Ecological Economics, 2004 (49): 431-455.

[4] Anna Chiesura, Rudolf de Groot. Critical natural capital: a socio-cultural perspective. Ecological Economics, 2003, 44(23): 219-231.

[5] Gareth Edwards-Jones, Ben Davies, Salman Hussain. Ecological economics: an Introduction. 0xford; Malden, MA: Blackwell Science, 2000: 1-13.

[6] In-Seek Kwak, Jeonghee Park. A Willingness to Move to an Ecological City. Journal of Korean Home Economics Association English Edition, 2001, 2(1): 1-16.

[7] 罗会永. 城市化与城市生态耦合关系研究 [J]. 合作经济与 科技, 2009 (23) : 16-18。

[8] 安瓦尔 - 买买提明, 张小雷, 塔世根 - 加帕尔. 基于模糊数学 的新疆南疆地区城市化与生态环境的和谐度分析 [J]. 经济 地理, 2010, 30 (2):214-219。

[9] 陈健, 查良松, 黄艳妮, 祝凤霞. 安徽省城市化与生态环境和 谐度分析 [J]. 安徽师范大学学报, 2011 (6) :568-573。
[10] 刘少博, 魏春雨, 郭娅琦等. Exploring harmonious development between urbanization and eco-environment based on climate analysis-A study in Changsha, China [J]. J. Cent. South Univ. Technol, 2011 (18) : 101-107.

[11] 丁婷红. 新疆南部中心城市城市化与生态环境对比研究 $[J]$. 石家庄学院学报, 2012, 14 (3) : 89-95。

[12] 王静, 赵德芳, 彭亚坤. 汉中市城市化与生态环境发展协调 性定量评价 [J]. 西北大学学报, 2012, 42 (3) : 466-470。

[13] 冯兰刚, 都沁军. 试论城市化发展对水资源的胁迫 $[\mathrm{J}]$. 湖南 财经高等专科学校学报, 2009, 25(118) : 93-95。

[14] 乔标, 方创琳, 李铭. 干旱区城市化与生态环境交互胁迫过 程研究进展与展望 $[\mathrm{J}]$. 地理科技进展, 2005, 24 (6) : 31-41。

[15] 白艳莹. 苏锡常地区城市化过程的生态环境胁迫作用 [D]. 硕士学位论文, 2002。

[16] 邹仁爱, 陈俊鸿. 城市胁迫发展理论--城市可持续发展的生 态学视角 $[J]$. 城市问题, 2005 (6) : 16-20。

[17] 郭娅琦. 城市化进程对城市生态环境的影响研究 [D]. 硕士 学位论文, 2007。

[18］周玄德, 孜比布拉 - 司马义. 吐鲁番市城市化与生态环境动 态分析 [J]. 水土保持研究, 2012, 19 (1) :159-163。

[19] 路春燕, 卫海燕, 白俊燕. 基于BP神经网络的城市化发展生 态环境压力响应研究-一以延安市为例 $[\mathrm{J}]$. 干旱区资源与环 境, 2012.26(4):61-66。

[20］李云, 谭文兵. 城市化发展对资源环境的影响与未来路径选 择 $[J]$. 当代经济, 2012(7):4-5。

[21] 郝华勇. 基于主成分分析法的武汉城市圈城镇化质量实证 研究 $[J]$. 武汉科技大学学报, 2012, 14 (3) :291-294。

[22] 王新杰, 薛东前, 延军平等. 西安市城市化与生态环境动态 关系分析 [J]. 地球与环境, 2010, 38(1) :43-48。

[23] 刘涁. 江西省城市化与生态环境关系的动态计量分析 [J]. 资源科学, 2008, 30 (6) : 829-836。

[24] 崔利芳, 仁学慧. 青岛市城市化与生态环境发展协调性的定 量评价 $[J]$. 云南地理环境研究, 2010, 22(4):77-81。 